\title{
Disentangling the Changes in the Indian Ocean Dipole-Related SST and Rainfall Variability under Global Warming in CMIP5 Models
}

\author{
PING HUANG \\ Center for Monsoon System Research and State Key Laboratory of Numerical Modeling for Atmospheric Sciences \\ and Geophysical Fluid Dynamics, Institute of Atmospheric Physics, Chinese Academy of Sciences, \\ and Joint Center for Global Change Studies, Beijing, China \\ XIAO-TONG ZHENG \\ Physical Oceanography Laboratory/Center of Marine Science and Technology, Ocean University of China \\ and Qingdao National Laboratory for Marine \\ Science and Technology, and Key Laboratory of Ocean-Atmosphere Interaction and Climate in Universities \\ of Shandong, College of Oceanic and Atmospheric Sciences, Ocean University of China, Qingdao, China

\section{JUN YING} \\ State Key Laboratory of Satellite Ocean Environment Dynamics, Second Institute of Oceanography, \\ Ministry of Natural Resources, Hangzhou, China
}

(Manuscript received 10 December 2018, in final form 24 March 2019)

\begin{abstract}
This study disentangles the changes in Indian Ocean (IO) dipole (IOD)-related SST and rainfall variability under global warming projected by the RCP8.5 runs in 29 CMIP5 models. The IOD rainfall changes consist of the thermodynamic component due to the surface moisture increase and the dynamic component due to the changes in IODrelated circulation. The IOD circulation changes are dominated by the IOD SST changes, which were further clarified using the amplitude and structural decomposition. The amplitudes of IOD SST and circulation are both decreased at rates of around $7.2 \%$ and $13.7 \%{ }^{\circ} \mathrm{C}^{-1}$, respectively. The structural changes in IOD SST and circulation show a pattern with increases from the eastern to the western coast of the equatorial IO, similar to the pattern of socalled extreme IOD events in previous studies. Disentangling previous mechanisms and projections, we conclude that the increased atmospheric stability suppresses the amplitudes in IOD SST and circulation, whereas the positive IOD (pIOD)-like mean-state SST changes, leading to greater warming in the west than the east, mainly alter the structure of IOD SST and circulation. Both the amplitude and structural changes in the IOD SST and circulation are robust among the CMIP5 models, but their distinct patterns and out-of-step changes lead to an uncertain projection of IOD changes defined by the dipole mode index or EOF analysis in previous studies. Furthermore, the structural changes, dominated by the pIOD-like mean-state SST changes, are significantly correlated with the historical IOD amplitude among the models. Considering the commonly overestimated IOD amplitude as an emergent constraint, the structural changes in IOD SST and circulation should not be as robust as the original multimodel projection.
\end{abstract}

\section{Introduction}

The Indian Ocean dipole (IOD) mode is a dominant interannual variability of sea surface temperature (SST) anomalies in the tropical Indian Ocean (IO) (Saji et al. 1999; Webster et al. 1999; Yu and Rienecker 1999; Murtugudde et al. 2000). The IOD features a zonal dipole pattern of SST anomalies (SSTAs) between the

Corresponding author: Ping Huang, huangping@mail.iap.ac.cn eastern equatorial IO (EEIO) off Sumatra and Java and the western equatorial IO (WEIO). A positive IOD (pIOD) event is defined by negative SSTAs in the EEIO and positive SSTAs in the WEIO, and the SST pattern of a negative IOD is an approximate mirror opposite to a pIOD. The SST pattern of the IOD is coupled with surface wind anomalies and a dipole pattern of rainfall anomalies over the equatorial IO (e.g., Yamagata et al. 2004; Schott et al. 2009; Cai et al. 2013). The prominent circulation and rainfall anomalies associated with the 


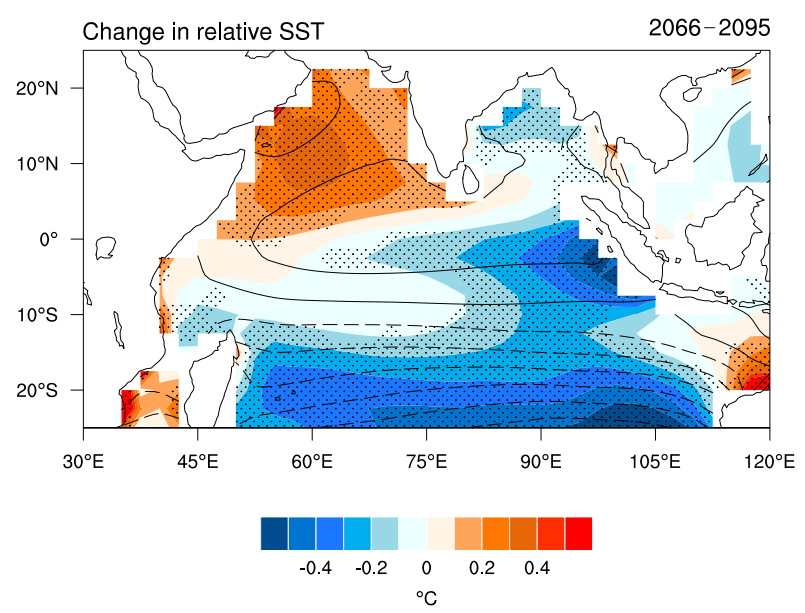

FIG. 1. Changes in the mean-state SST relative to the tropicalmean SST increase (shaded) in 2066-95. Stippling indicates that more than $70 \%$ of models agree on the sign of the MME changes. Contours are the mean-state SST relative to the tropical-mean SST in the historical runs (contour interval is $1^{\circ} \mathrm{C}$ and negative contours are dashed).

IOD often induce extreme disasters in the IO-rim regions (Ashok et al. 2003; Zubair et al. 2003; Behera et al. 2005; Kripalani et al. 2010).

The tropical IO also shows apparent warming with greenhouse gases increasing (e.g., Du and Xie 2008). How the IOD mode and its impact on regional climate will respond to global warming is one of the most significant issues (Ihara et al. 2009; Zheng et al. 2010; Cai et al. 2013; Zheng et al. 2013; Cai et al. 2014a). Apart from basin-uniform warming in IO, most state-of-the-art models project a robust pattern of mean-state SST changes with more warming in the WEIO and less in the EEIO, often called a pIOD-like pattern (Fig. 1) (Abram et al. 2008; Zheng et al. 2010, 2013; Liu et al. 2015; Luo et al. 2016). The pIOD-like mean-state SST changes will shoal the thermocline in the EEIO and deepen that in the WEIO, and the shoaling thermocline in the EEIO can enhance the local thermocline feedback, leading to an intensified local SST variability (Abram et al. 2008; Zheng et al. 2010). In contrast, global mean warming can increase the static stability of the tropical atmosphere (Knutson and Manabe 1995; Lu et al. 2008), leading to a decreased air-sea interaction variability in the tropics (Zheng et al. 2013; P. Huang et al. 2017). The opposite roles of the two processes result in an uncertain change in IOD-related SST variability projected in state-of-theart models (Ihara et al. 2009; Cai et al. 2013; Zheng et al. 2013; Hui and Zheng 2018).

Although the changes in IOD-related SST variability (referred to simply as "IOD SST") are projected with large intermodel spread, some studies reported that the extreme pIOD events using a rainfall-based definition are likely to increase in a warmer climate (Cai et al. 2014a; Wang et al. 2017). The robust pIOD-like pattern in mean-state SST change (Fig. 1), with weakened equatorial westerly winds and eastward oceanic currents was suggested to cause increased frequency of extreme pIOD events (Cai et al. 2014a). The distinct projections of IOD SST and IOD-driven rainfall variability (hereafter referred to as "IOD rainfall") show that the relationship among the changes in IOD SST, IOD rainfall, and mean-state SST is still unclear.

There is a similar question with regard to the changes in ENSO-related SST and rainfall variability (Collins et al. 2010; Power et al. 2013). Recently, great progress has been made based on moisture budget decompositions for change in the interannual variability of tropical rainfall (Seager et al. 2012; Chung et al. 2014; Huang and Xie 2015; Huang 2016). A simplified moisture budget decomposition proposed in Huang and Xie (2015) defines change in the interannual variability of tropical rainfall as

$$
\Delta P^{\prime} \sim-\left(\Delta q \omega^{\prime}+q \Delta \omega^{\prime}\right)
$$

where $P$ is tropical rainfall, $\omega$ is pressure velocity at $500 \mathrm{hPa}$ representing vertical motion, $q$ is surface specific humidity, $\Delta$ denotes future change, and the prime denotes interannual variability. The term $\Delta q \omega^{\prime}$ due to the mean-state moisture change $\Delta q$ is defined as the thermodynamic component, and $q \Delta \omega^{\prime}$ due to the change in circulation variability $\Delta \omega^{\prime}$ is defined as the dynamic component. The moisture budget decomposition clearly presents the relationship among rainfall variability change $\Delta P^{\prime}$, circulation variability change $\Delta \omega^{\prime}$, and meanstate moisture change $\Delta q$ under global warming. Furthermore, for ENSO-related variability, the circulation variability change $\Delta \omega^{\prime}$ is closely tied to the SST variability change and mean-state SST change pattern (Huang and Xie 2015; Huang 2016). This decomposition was also applied to study the rainfall variability change in South America and North America (Tedeschi and Collins 2017; Dong et al. 2018). The effectiveness of the simplified moisture budget decomposition for analyzing ENSOrelated SST and rainfall variability provides a helpful method to disentangle the puzzling changes in IOD SST and IOD rainfall in a warmer climate.

In this study, we used the decomposition method in Huang and Xie (2015) to explore the mechanisms of IOD rainfall changes and the relationship with IOD SST changes, based on the outputs of 29 CMIP5 models in the historical and the $+8.5 \mathrm{~W} \mathrm{~m}^{-2}$ representative concentration pathway (RCP8.5) runs. Our analyses show that the moisture decomposition method is also 
practicable to IOD rainfall changes: the thermodynamic component due to the mean-state moisture increase and the dynamic component due to IOD circulation changes can accurately describe the pattern of IOD rainfall changes. The relationship between changes in IOD circulation and IOD SST is also disentangled based on an amplitude and structural decomposition with an intermodel correlation analysis.

The rest of the paper is organized as follows. Section 2 describes the CMIP5 models and methods; section 3 presents the thermodynamic and dynamic decomposition of IOD rainfall changes; the relationship between changes in IOD SST and IOD circulation is presented in section 4; section 5 discusses the intermodel spread of changes in IOD-related variability projected in CMIP5; and conclusions and discussions are given in section 6 .

\section{Models and methods}

The models, the definition of climatology and interannual anomaly, the moisture budget decomposition, and the amplitude and structural decomposition used in the present study are similar to that in Huang and Xie (2015) and Huang (2016), and are briefly reviewed here. The following introduction of the models and methods is derived from Huang (2016) with minor modifications.

\section{a. Models and the definition of climatology and IOD-related variability}

This study used the historical runs from 1971 to 2005 and the RCP 8.5 runs from 2006 to 2100 from 29 models of the CMIP5 (Taylor et al. 2012). The 29 models are ACCESS1.0, ACCESS1.3, BCC_CSM1.1, BCC_CSM1.1(m), BNU-ESM, CanESM2, CCSM4, CESM1(BGC), CMCC-CESM, CMCC-CM, CMCCCMS, CNRM-CM5, GFDL CM3, GFDL-ESM2G, GFDL-ESM2M, GISS-E2-H, GISS-E2-R, HadGEM2ES, IPSL-CM5A-LR, IPSL-CM5A-MR, IPSL-CM5BLR, MIROC5, MIROC-ESM, MIROC-ESM-CHEM, MPI-ESM-LR, MPI-ESM-MR, MRI-CGCM3, NorESM1$\mathrm{M}$, and NorESM1-ME (expansions of acronyms are available online at http://www.ametsoc.org/PubsAcronymList). The oceanic and atmospheric outputs in all models were interpolated onto a $2.5^{\circ} \times 2.5^{\circ}$ grid, which is effective for the large-scale interannual variability.

The calculation of interannual anomalies followed Zheng et al. (2013), removing the seasonal cycle, performing a 3-month running mean, and removing the 9-yr running mean. Then, the 1976-2005 period was selected as the current climate, and the eighteen 30-yr segments starting from 1981 with 5-yr leaps (i.e., 19812010, 1986-2015, 1991-2020, . . , 2061-90, 2065-95) were selected as periods in the warming climate, and the beginning and ending 5-yr data were abandoned. The mean of each 30-yr segment in the RCP8.5 runs and the 1976-2005 in the historical runs defined the respective climatology. Here, the 30 -yr division does not influence the conclusions. Because IOD typically matures in the months from September to November (SON) in observations and CMIP5 models (e.g., Zheng et al. 2013), we calculated the SON seasonal mean of the filtered SST anomalies to extract the IOD in the following steps. Considering the discrepancies of model simulation skill for the SST pattern of IOD, we defined the IOD pattern using the dipole mode index (DMI; Saji et al. 1999), which is the different regional-mean SST anomalies in the WEIO $\left(50^{\circ}-70^{\circ} \mathrm{E}, 10^{\circ} \mathrm{S}-10^{\circ} \mathrm{N}\right)$ minus the EEIO $\left(90^{\circ}-110^{\circ} \mathrm{E}, 10^{\circ} \mathrm{S}-0^{\circ}\right)$, the two green boxes in Fig. 2a. The interannual anomalies of SST, rainfall, and circulation were regressed onto the standardized DMI to define IOD SST, IOD rainfall, and IOD circulation for each model and each 30-yr segment.

The average of all models defines the multimodel ensemble mean (MME). Four popular SST observation datasets were used to measure IOD amplitude in observations. They are NOAA ERSST version 4 from https://www1.ncdc.noaa.gov/pub/data/cmb/ersst/v4/netcdf/ (B. Huang et al. 2015), NOAA ERSST version 5 from https://www1.ncdc.noaa.gov/pub/data/cmb/ersst/v5/netcdf/ (B. Huang et al. 2017), HadISST from https://www. metoffice.gov.uk/hadobs/hadisst/ (Rayner et al. 2003), and COBE SST2 from https://www.esrl.noaa.gov/psd/ data/gridded/data.cobe2.html (Hirahara et al. 2014).

\section{b. Decompositions for IOD rainfall changes}

Moisture budget decomposition is often used to investigate the formation mechanism of tropical rainfall changes in climatological mean state (Held and Soden 2006; Chou et al. 2009; Seager et al. 2010; Huang et al. 2013; Huang 2014) and in interannual variation (Seager et al. 2012; Chung et al. 2014; Huang and Xie 2015). In the present study, we applied the simplified moisture budget decomposition method proposed in Huang and Xie (2015) [Eq. (1)] to study IOD rainfall changes. In Eq. (1), the constant coefficient of the moisture budget equation is omitted for simplicity, as in previous studies (Huang et al. 2013; Huang and Xie 2015). Resultantly, the units on the two sides of Eq. (1) differ by a constant, which does not influence the conclusions.

Following Huang and Xie (2015) and Huang (2016), the changes in IOD circulation $\Delta \omega^{\prime}$ can be further decomposed into amplitude and structural changes: $\Delta \omega^{\prime}=\Delta \omega_{a}^{\prime}+\Delta \omega_{s}^{\prime}$. The amplitude changes $\Delta \omega_{a}^{\prime}$ were obtained by projecting the total $\Delta \omega^{\prime}$ onto the historical $\omega^{\prime}$, and the residual was defined as the structural changes $\Delta \omega_{s}^{\prime}$. Similarly, the changes in IOD SST $\Delta T^{\prime}$ were 
(a) IOD SST

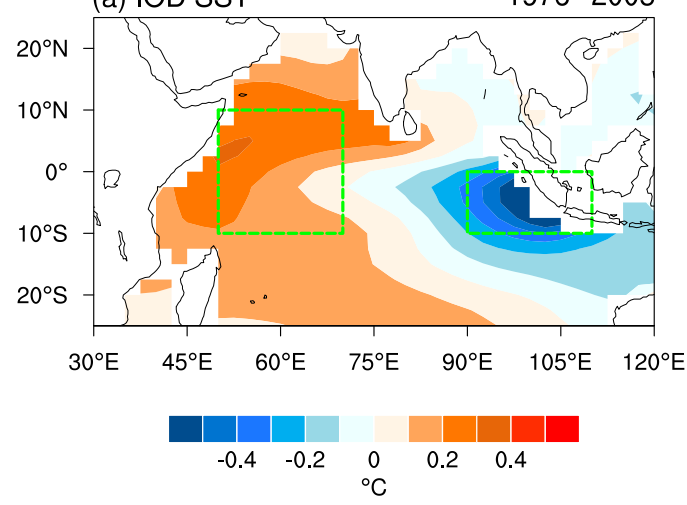

(c) Change in IOD SST

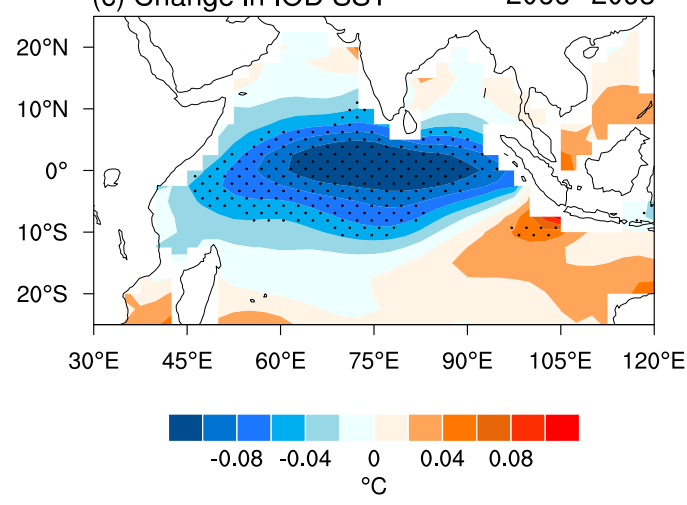

(b) IOD rainfall
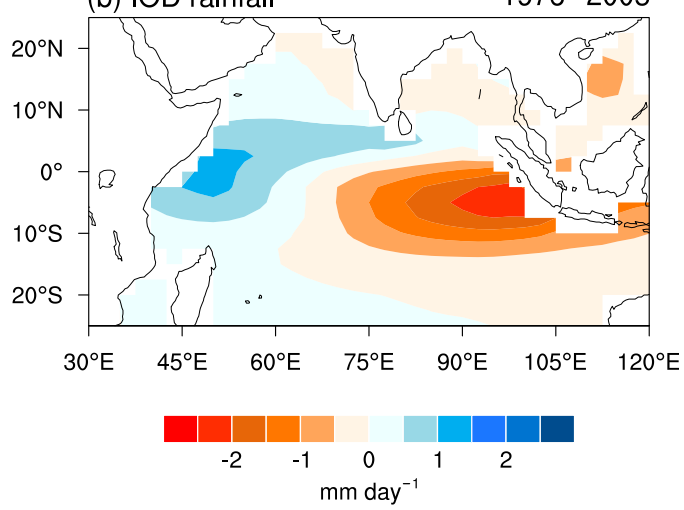

(d) Change in IOD rainfall $\quad 2066-2095$

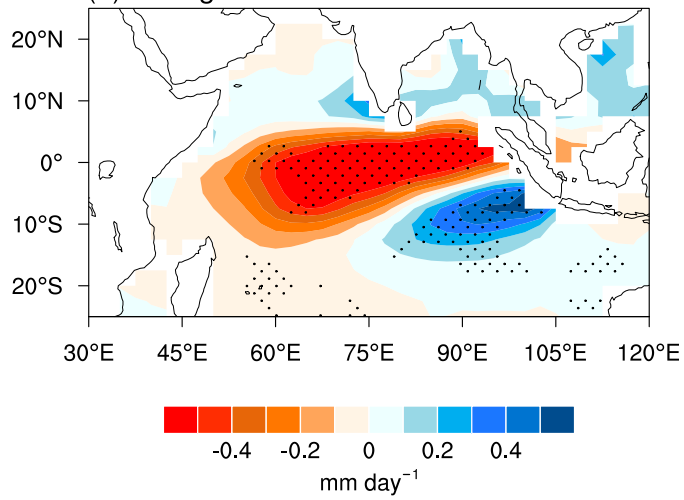

FIG. 2. The simulated historical (a) IOD-related SST anomalies and (b) IOD-induced rainfall anomalies in the MME, and (c),(d) their changes for the period 2066-95 in the RCP8.5 runs. Stippling in (c) and (d) indicates that more than $70 \%$ of models agree on the sign of the MME changes. The green boxes in (a) indicate the regions to calculate the DMI.

decomposed as $\Delta T^{\prime}=\Delta T_{a}^{\prime}+\Delta T_{s}^{\prime}$. With the decomposition of IOD circulation changes, changes in IOD rainfall can be written as

$$
\Delta P^{\prime} \sim-\left[\Delta q \omega^{\prime}+\left(q \Delta \omega_{a}^{\prime}+q \Delta \omega_{s}^{\prime}\right)\right],
$$

where $\Delta q \omega^{\prime}$ is the thermodynamic component, $q \Delta \omega_{a}^{\prime}$ represents the amplitude changes in the dynamic component, and $q \Delta \omega_{s}^{\prime}$ the structural changes in the dynamic component.

\section{IOD rainfall changes and moisture budget decomposition}

Figures $2 \mathrm{a}$ and $2 \mathrm{~b}$ show the patterns of IOD SST and IOD rainfall, respectively, of the MME simulated in the CMIP5 models. The models' performance in reproducing the IOD mode has been evaluated in previous studies (e.g., Zheng et al. 2013). The CMIP5 models can basically reproduce a realistic IOD mode. Here, the IOD SST and rainfall patterns were defined by the regression of the standardized DMI. As a result, the defined IOD-related patterns must be closer to the observations than the definition based on empirical orthogonal function (EOF) analysis in Zheng et al. (2013), especially for the models with a relatively unrealistic IOD pattern. On the other hand, the IOD SST is overestimated in the models compared with the observation, as reported in previous studies (Cai and Cowan 2013; Liu et al. 2014; Li et al. 2015).

The MME changes in IOD SST and IOD rainfall in the period of 2066-95 of the RCP8.5 run are shown in Figs. $2 \mathrm{c}$ and $2 \mathrm{~d}$, respectively. The pattern of IOD SST changes is roughly opposite that of the pIOD pattern (Fig. 2a). However, differing from the pIOD pattern, the western negative SST changes extend to the eastern coast of the equatorial IO and are much stronger than the positive SST changes off the Sumatra-Java coast, whereas the positive SST changes are only located in the Southern Hemisphere. The pattern of IOD SST changes will be discussed in section 4 in detail. For the IOD rainfall changes $\Delta P^{\prime}$, there are robust negative rainfall changes extending from the EEIO to the western coast 
(a) $\Delta q \cdot \omega^{\prime}$

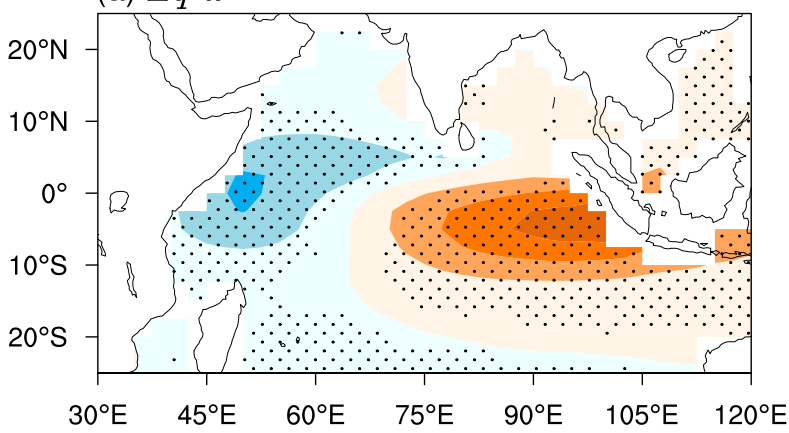

(b) $q \cdot \Delta \omega^{\prime}$

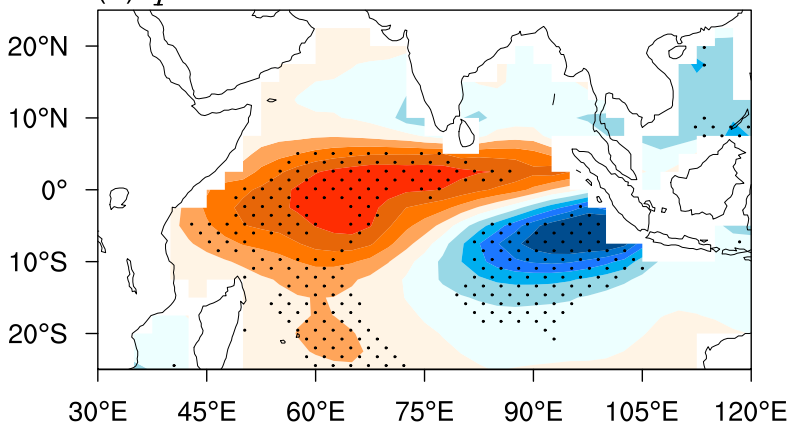

(c) $\Delta q \cdot \omega^{\prime}+q \cdot \Delta \omega^{\prime}$

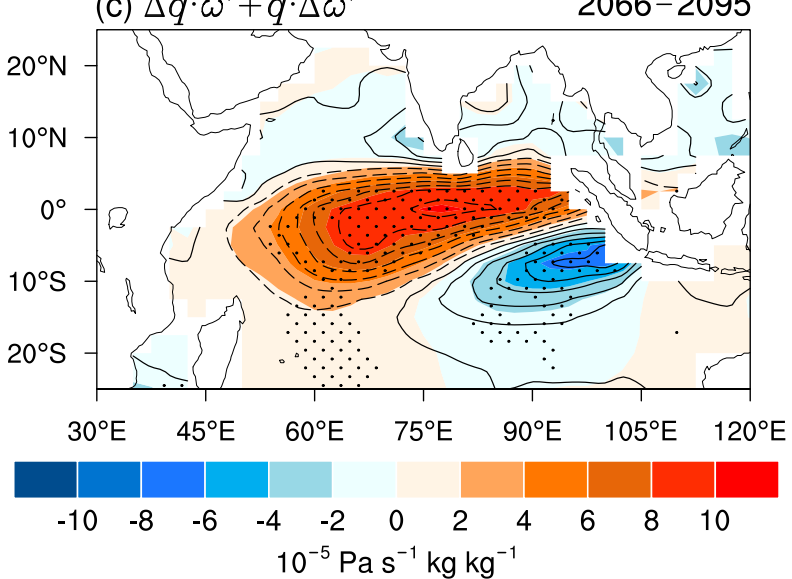

FIG. 3. The (a) thermodynamic and (b) dynamic components and (c) their sums of changes in IOD rainfall in the RCP8.5 runs. Contours in (c) are the changes in IOD rainfall (contour interval is $0.1 \mathrm{~mm} \mathrm{day}^{-1}$, and negative contours are dashed). Stippling indicates that more than $70 \%$ of models agree on the sign of the MME changes.

of the equatorial IO and weak positive rainfall in the southeastern IO. The pattern of $\Delta P^{\prime}$ is similar to the pattern of extreme pIOD events defined by the second mode of EOF analysis for the rainfall anomalies in Cai et al. (2013), and consists of the projection of increased frequency of extreme pIOD events. The $\Delta P^{\prime}$ pattern basically corresponds to the $\Delta T^{\prime}$ pattern, except that the range of negative SST changes in $\Delta T^{\prime}$ is wider than that of the negative rainfall changes in $\Delta P^{\prime}$.

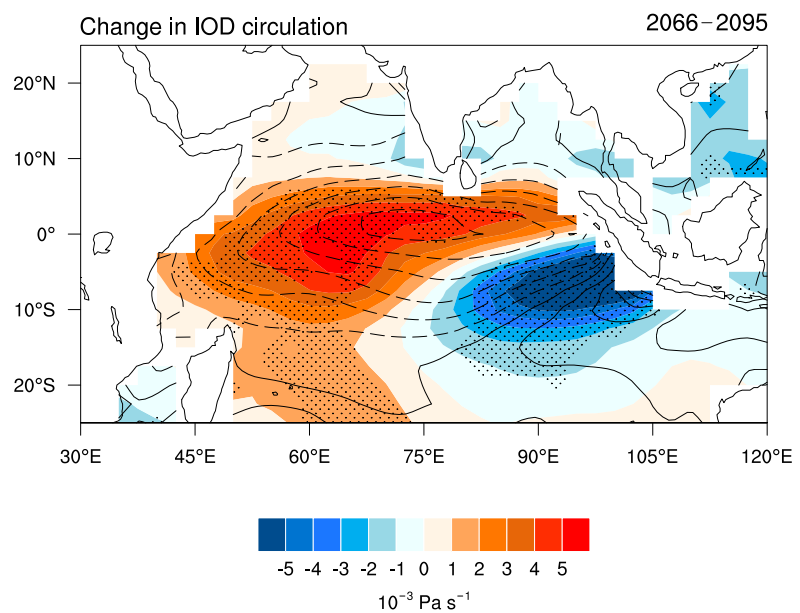

FIG. 4. Changes in IOD circulation (shaded) and IOD SST (contours) in the RCP8.5 runs. The contour interval is $0.02^{\circ} \mathrm{C}$, and negative contours are dashed. Stippling indicates that more than $70 \%$ of models agree on the sign of the MME changes.

Following the moisture budget decomposition, the total $\Delta P^{\prime}$ is decomposed into the thermodynamic $\left(\Delta q \omega^{\prime}\right.$; Fig. 3a) and dynamic $\left(q \Delta \omega^{\prime}\right.$; Fig. 3b) components. The pattern of the thermodynamic component is identical to the historical IOD circulation and rainfall (Fig. 2b) because the spatial gradient of mean-state moisture changes is much weaker than that of the historical IOD circulation. As a result, the thermodynamic component due to the surface moisture increase enhances IOD rainfall with the increase rate of surface moisture under global warming, around $7 \%-8 \%{ }^{\circ} \mathrm{C}^{-1}$ following the Clausius-Clapeyron relationship. On the other hand, the dynamic component of $\Delta P^{\prime}$ due to the IOD circulation changes $\Delta \omega^{\prime}$ shows a pattern with decreases extending from the EEIO to the western coast of the equatorial IO and weak increases in the southeastern IO, following the pattern of $\Delta \omega^{\prime}$ (Fig. 4). The sum of the thermodynamic and dynamic components (Fig. 3c) accurately describes the pattern of $\Delta P^{\prime}$ (Fig. 2d and contours in Fig. 3c), indicating the simplified moisture budget decomposition [Eq. (1)] proposed in Huang and Xie (2015) for ENSO rainfall changes is also feasible for the IOD rainfall changes. The magnitude of the dynamic component (Fig. 3b) is around twice that of the thermodynamic component (Fig. 3a) and thus basically dominates the total $\Delta P^{\prime}$ (Fig. 3c). The contribution of the thermodynamic component is visible off the eastern coast of Africa and the western coast of Sumatra and Java. Obviously, the sum of the thermodynamic and dynamic components (Fig. 3c) is closer to $\Delta P^{\prime}$ than the dynamic component (Fig. 3b), showing that the thermodynamic component cannot be ignored. 

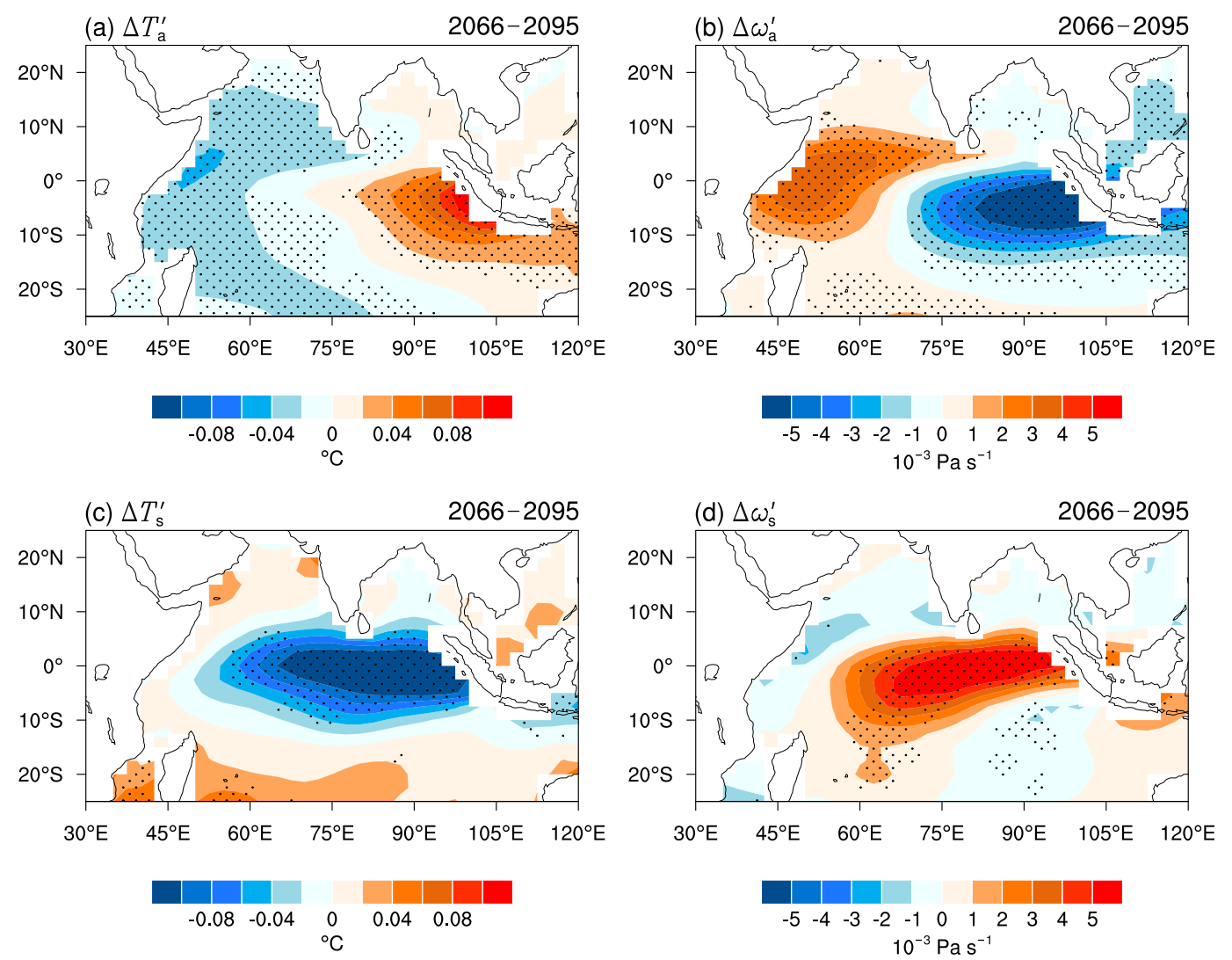

FIG. 5. The (top) amplitude and (bottom) structural changes in the (a),(c) IOD SST and (b),(d) IOD circulation in the RCP8.5 runs. Stippling indicates that more than $70 \%$ of models agree on the sign of the MME changes.

\section{Amplitude and structural decomposition for IOD SST and circulation}

From Fig. 4, the pattern of IOD circulation changes $\Delta \omega^{\prime}$ is roughly consistent with that of IOD SST changes $\Delta T^{\prime}$, both enhanced off the Sumatra-Java coast and decreased from the EEIO to the WEIO. On the other hand, the patterns of $\Delta T^{\prime}$ and $\Delta \omega^{\prime}$ exhibit apparent discrepancies, especially the opposite changes at around $80^{\circ}-100^{\circ} \mathrm{E}$ and $10^{\circ} \mathrm{S}-0^{\circ}$. Following the amplitude and structural decomposition introduced in section $2 \mathrm{c}$, we decomposed $\Delta T^{\prime}$ and $\Delta \omega^{\prime}$ into amplitude and structural changes, respectively. Dependent on the decomposition method, the amplitude changes of IOD SST $\left(\Delta T^{\prime}{ }_{a}\right.$; Fig. 5a) have an identical pattern to the historical IOD SST (Fig. 2a), whereas the structural changes of IOD SST $\left(\Delta T_{s}^{\prime}\right.$; Fig. $\left.5 \mathrm{c}\right)$ are spatially orthogonal to the historical IOD SST. Similarly, the pattern of the amplitude changes of IOD circulation $\left(\Delta \omega_{a}^{\prime}\right)$ is identical to that of historical IOD circulation, and the pattern of the structural changes of IOD circulation $\left(\Delta \omega_{s}^{\prime}\right)$ is orthogonal to the historical IOD circulation (not shown). Both $\Delta T^{\prime}{ }_{a}$ and $\Delta \omega^{\prime}{ }_{a}$ show a robust decrease relative to the pIOD pattern (Figs. 2a and 5a,b), which could be induced by the increased static stability (Knutson and Manabe 1995; Lu et al. 2008; Zheng et al. 2013; P. Huang et al. 2017). The pattern of $\Delta \omega^{\prime}$ is closely consistent with that of $\Delta T_{s}^{\prime}$, both of which are similar to the pattern of extreme pIOD defined in Cai et al. (2014a).

The intermodel agreement test suggests that both $\Delta T^{\prime}{ }_{a}$ and $\Delta T^{\prime}{ }_{s}$ are robust among the models, which seems controversial given the conclusion that the IOD SST changes are not robust in the CMIP5 projections (Cai et al. 2013; Zheng et al. 2013). This result can be explained by the distinct patterns of $\Delta T^{\prime}{ }_{a}$ and $\Delta T^{\prime}{ }_{s}$, which are a zonal dipole pattern and a monopole pattern with maximum in the central-eastern equatorial IO, respectively. Especially, $\Delta T_{s}^{\prime}$ is opposite to $\Delta T_{a}^{\prime}$ off the Sumatra-Java coast, the EEIO domain to calculate DMI, resulting in the nonrobust changes in IOD SST in the EEIO (Fig. 2c). To illustrate the robustness more clearly, we further calculated an IOD SST change index, which represents the different regional-mean IOD SST changes in the WEIO $\left(50^{\circ}-70^{\circ} \mathrm{E}, 10^{\circ} \mathrm{S}-10^{\circ} \mathrm{N}\right)$ minus the EEIO $\left(90^{\circ}-110^{\circ} \mathrm{E}, 10^{\circ} \mathrm{S}-0^{\circ}\right)$, that is, the two green boxes for calculating DMI in Fig. 2a. The IOD SST change 
(a) Change in IOD SST

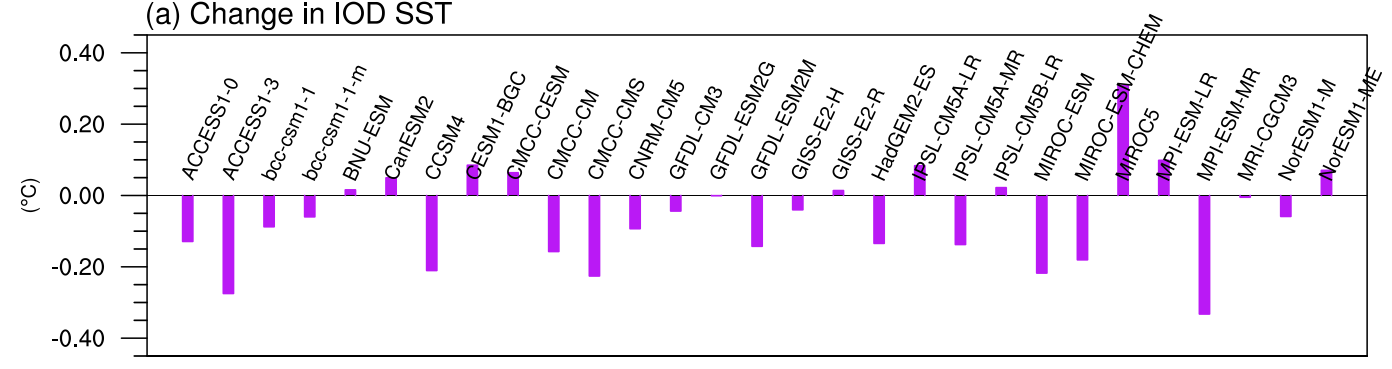

(b) Change in EEIO SST

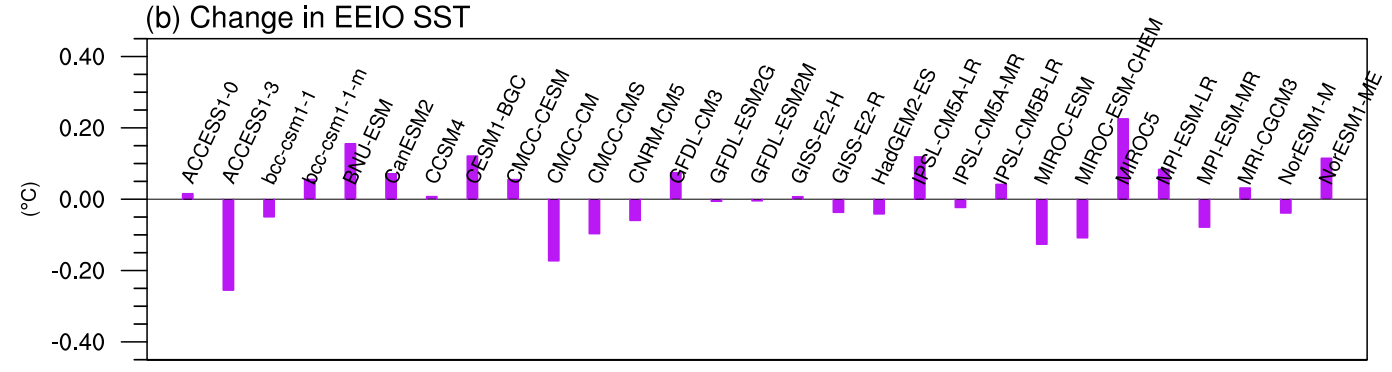

(c) Amplitude change in IOD SST

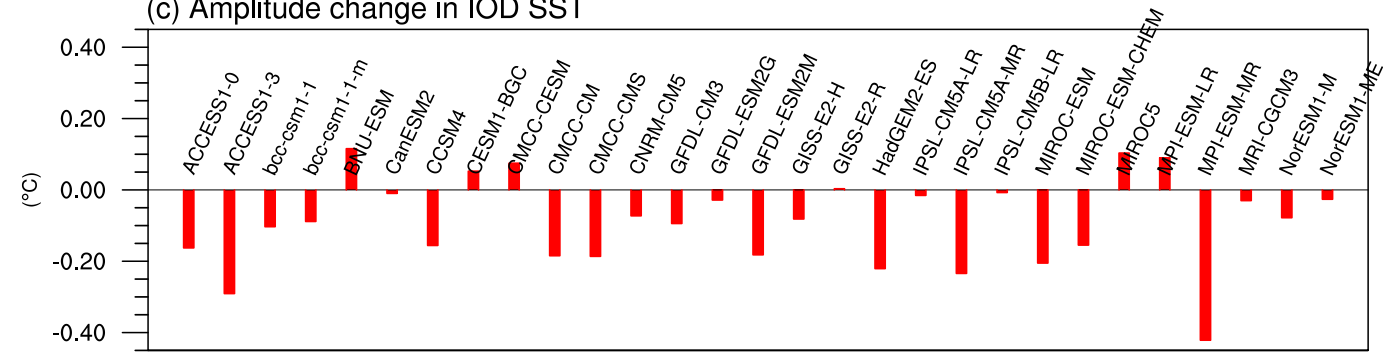

(d) Structural change in IOD SST

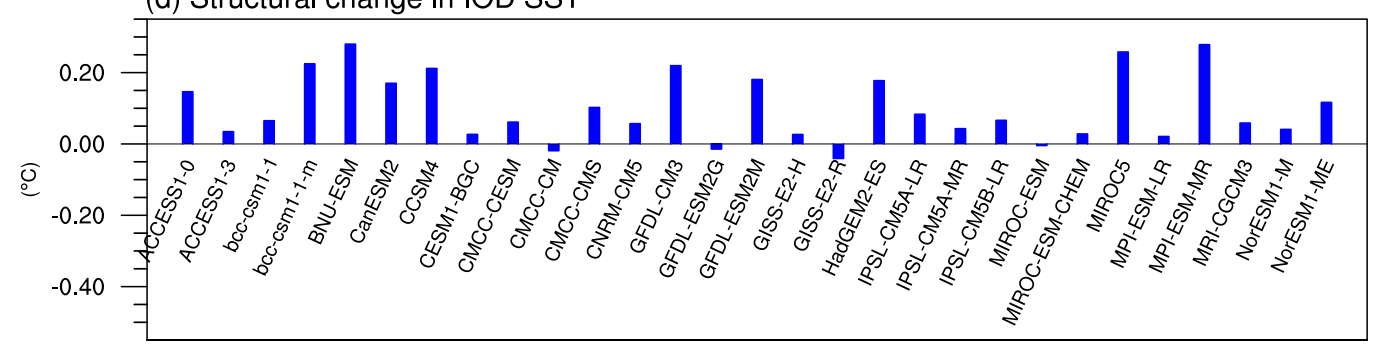

FIG. 6. (a) The total change in IOD SST, (b) change in EEIO SST, (c) amplitude change in IOD SST, and (d) structural change in IOD SST in the 29 models.

index is equal to the change in the standard deviation of DMI, hereafter referred to as the total DMI change. In Fig. 6a, the total DMI changes show an apparent intermodel spread, increased in 10 models and decreased in 19 models. The regional mean of IOD SST changes in the EEIO domain $\left(90^{\circ}-110^{\circ} \mathrm{E}\right.$ and $\left.10^{\circ} \mathrm{S}-0^{\circ}\right)$ has similarly large intermodel spread (Fig. 6b), with an increase (decrease) in 15 (14) models. In contrast, the DMI mean of $\Delta T_{a}^{\prime}$ has very high intermodel agreement (Fig. 6c), being increased (decreased) in 6 (23) models; and $\Delta T^{\prime}{ }_{s}$ represented by the regional mean over the central equatorial IO $\left(60^{\circ}-100^{\circ} \mathrm{E}, 5^{\circ} \mathrm{S}-5^{\circ} \mathrm{N}\right)$ is increased (decreased) in 25 (4) models (Fig. 6d).

Apart from the MME analysis, the intermodel relationship analysis is an effective way to study the mechanism of regional climate change (e.g., Huang and Xie 2015), which is further used to study the relationship between the changes in IOD SST and circulation. In 
(a)

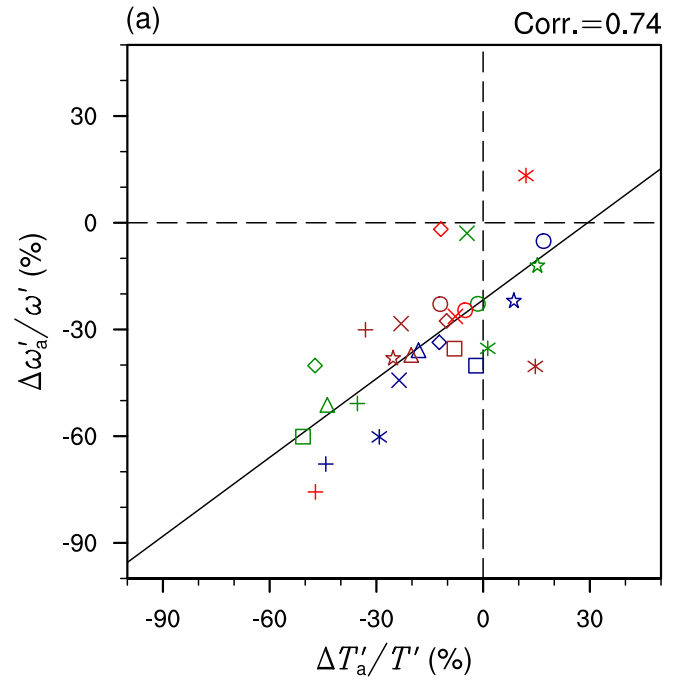

(c)

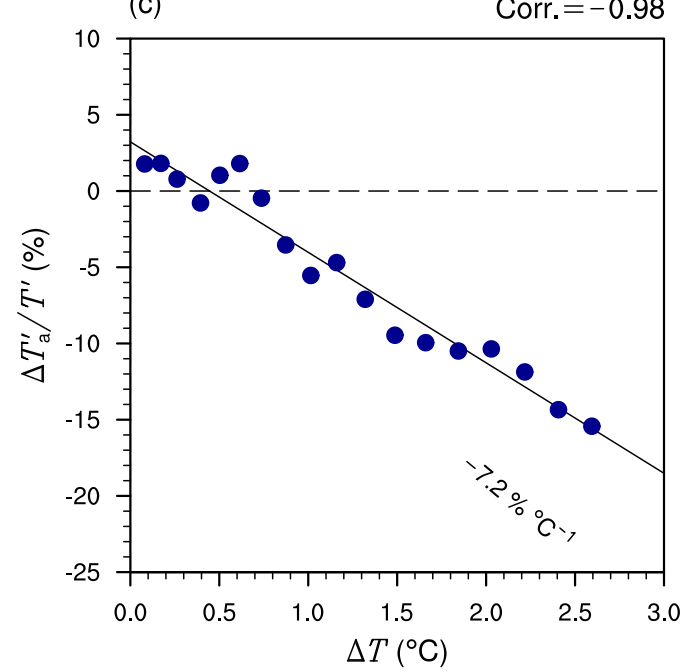

(b)

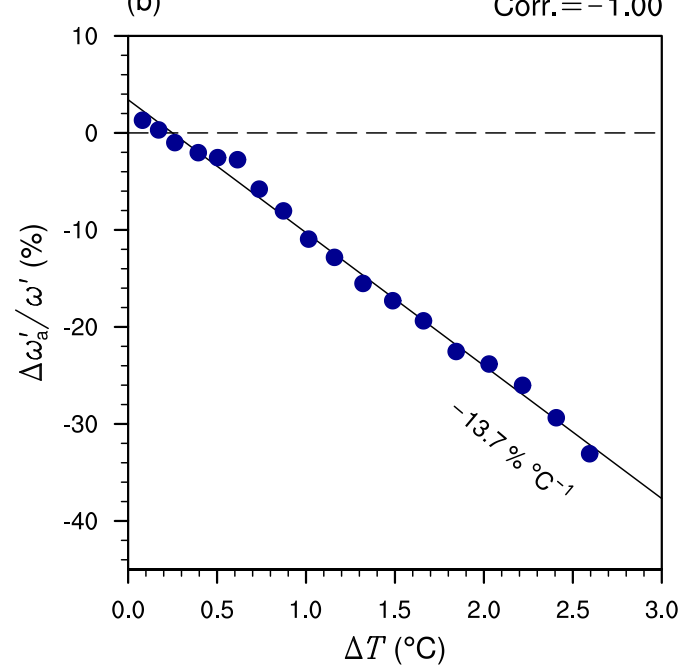

(d)

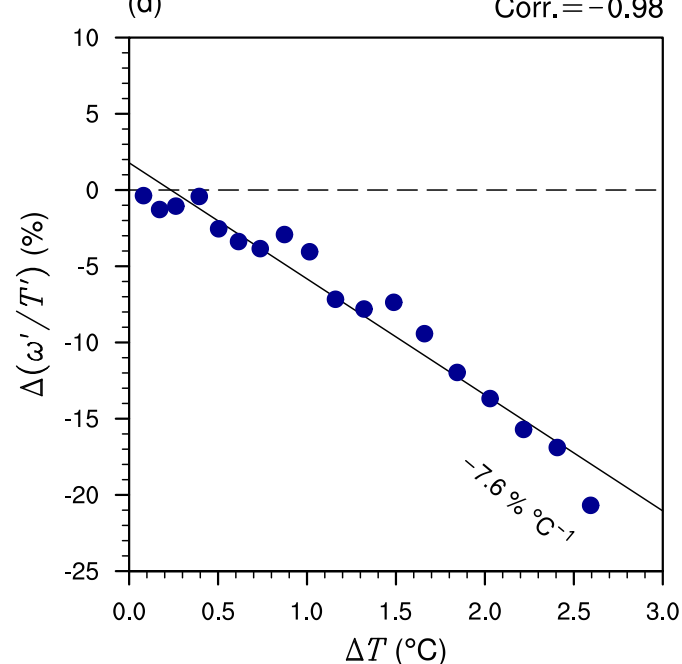

○ IPSL-CM5B-LR

$\square$ MIROC-ESM

$\triangle$ MIROC-ESM-CHEM

is MIROC5

* MPI-ESM-LR

FIG. 7. (a) Relationship between the amplitude change percentages in IOD circulation and in IOD SST in 206695 of the RCP8.5 runs among the 29 models, and the amplitude change percentages in (b) IOD circulation, (c) IOD SST, and (d) the response of IOD circulation to IOD SST with the structural changes removed in the 18 periods from 1981-2010 to 2066-95 with the tropical-mean SST increase. The solid line denotes the linear regression, and the correlation coefficient is shown at the top-right corner of each panel.

Fig. 7a, the change percentage of $\Delta \omega_{a}^{\prime}$ is significantly correlated with that of $\Delta T_{a}^{\prime}$ in the 29 models, indicating the dominant role of $\Delta T_{a}^{\prime}$ in the intermodel spread of $\Delta \omega_{a}^{\prime}$. It is noteworthy that the intercept of the $\Delta \omega_{a}^{\prime}-\Delta T_{a}^{\prime}$ linear regression is not zero but around $-21.7 \%$ at $2.6^{\circ} \mathrm{C}$ tropical-mean warming during 2066-95 in RCP8.5 runs (Fig. 7a). The negative intercept of the $\Delta \omega_{a}^{\prime}-\Delta T_{a}^{\prime}$ linear regression indicates a faster decrease of $\Delta \omega_{a}^{\prime}$ than $\Delta T_{a}^{\prime}$. Separately considered, $\Delta \omega_{a}^{\prime}$ decreases at a rate of around $13.7 \%$ per $1^{\circ} \mathrm{C}$ tropical-mean warming (Fig. $7 \mathrm{~b}$ ), and the rate for $\Delta T_{a}^{\prime}$ is around $7.2 \%{ }^{\circ} \mathrm{C}^{-1}$ (Fig. 7c). As a result, the response of IOD circulation to IOD SST decreases at a rate of around $7.6 \%{ }^{\circ} \mathrm{C}^{-1}$ (Fig. $7 \mathrm{~d}$ ), which is close to the Clausius-Clapeyron relationship. These change rates reveal that the increased atmospheric stability under global warming, following the Clausius-Clapeyron relationship (Knutson and Manabe 1995), directly influences the response efficiency of 
(a)

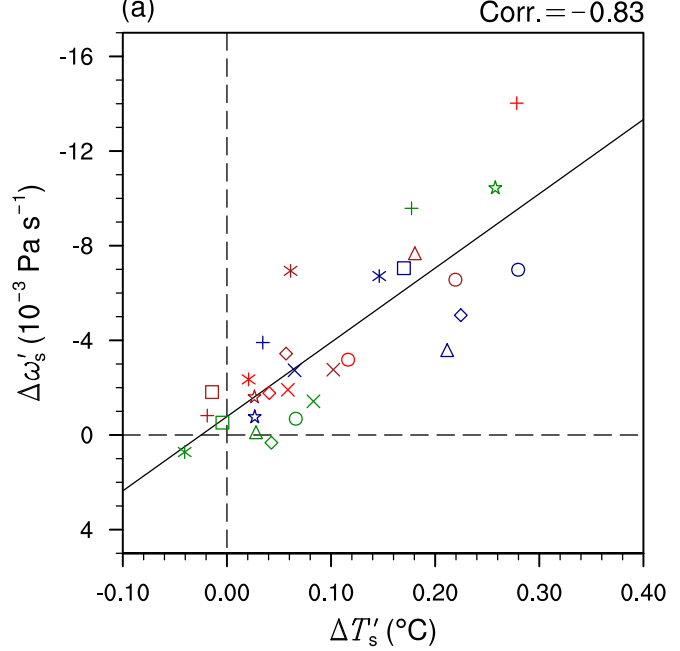

(c)

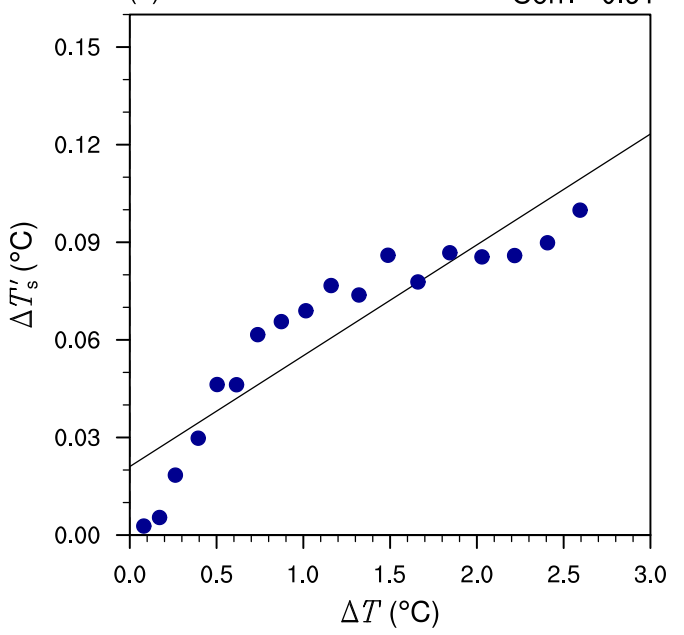

(b)

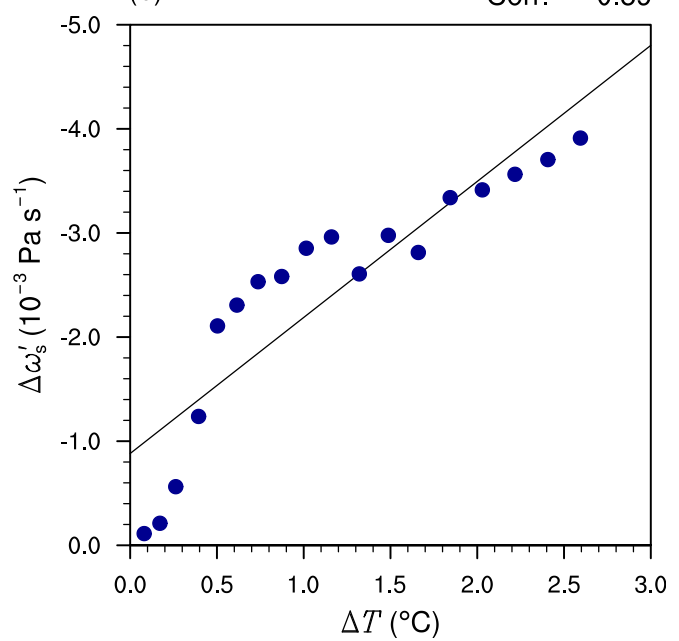

(d)

Corr $=0.09$

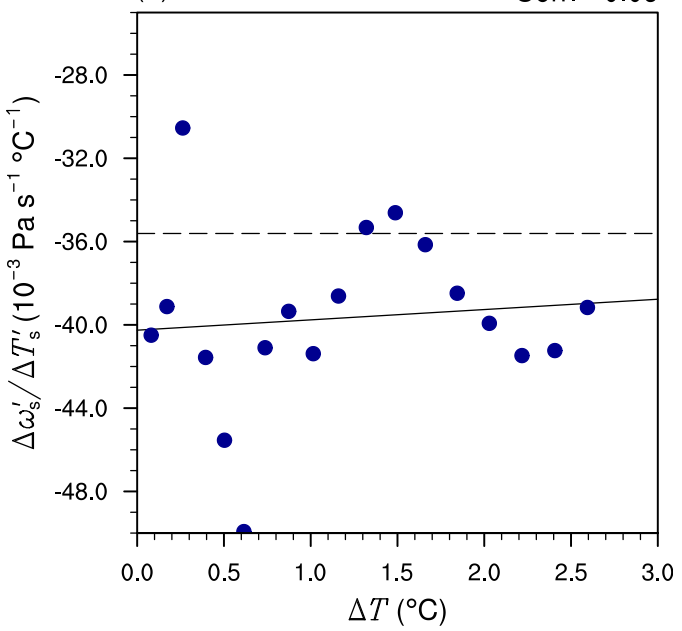

FIG. 8. (a) Intermodel relationship between the EEIO index of the structural changes in IOD circulation and that in IOD SST, the EEIO index of the structural changes in (b) IOD circulation and (c) IOD SST, and (d) the response of IOD circulation structural changes to IOD SST structural changes with the tropical-mean SST increase in the 18 periods from 1981-2010 to 2066-95. The solid line denotes the linear regression, and the correlation coefficient is shown in the top-right corner of each panel.

atmospheric circulation to external forcing (P. Huang et al. 2017), such as the SST anomalies here. Weakening of the IOD circulation response to IOD SST in turn influences the SST variability through the Bjerknes feedback. This process is robust among the models and does not depend on the model's mean-state performance. On the other hand, the response of SST variability to atmospheric anomalies would be enhanced under global warming, which could be induced by the uniform decrease in the thermocline depth with the increased temperature stratification in the ocean subsurface (Pierce et al. 2006; Capotondi et al. 2012; P. Huang et al. 2015). The decreased response of circulation to SST anomalies is the dominant source of the decreased IOD SST amplitude under global warming, but must be balanced by the enhancement process to form a stable change in IOD SST and circulation variability.

Similar to the relationship between $\Delta \omega_{a}^{\prime}$ and $\Delta T_{a}^{\prime}$, the structural changes in IOD circulation $\Delta \omega_{s}^{\prime}$ are also significantly correlated with the structural changes in IOD SST $\Delta T_{s}^{\prime}$ (Fig. 8a). Both $\Delta \omega_{s}^{\prime}$ and $\Delta T_{s}^{\prime}$ are linearly enhanced along with the tropical-mean SST increase during the calculation periods (Figs. 8b,c), but they also show different rates in the early and late twenty-first century, reflecting the non-unidirectional response of mean SST to global warming over the Indo-Pacific basin (Kim et al. 2014). In contrast to the progressive decrease 
in the amplitude of IOD circulation response to IOD SST (Fig. 7d), the strength of $\Delta \omega_{s}^{\prime}$ response to $\Delta T_{s}^{\prime}$ almost does not vary along the enhancement of global warming (Fig. 8d) and stays around the historical response strength of the IOD circulation to the IOD SST (dashed line in Fig. 8d). This result indicates that the atmospheric static stability changes and other possible mechanisms do not contribute to $\Delta \omega_{s}^{\prime}$, and that $\Delta \omega_{s}^{\prime}$ is dominated by $\Delta T_{s}^{\prime}$. The relationship between IOD-related $\Delta T^{\prime}{ }_{s}$ and $\Delta \omega_{s}^{\prime}$ is different from that between the structural changes in ENSO-related SST and circulation (Huang and Xie 2015; Huang 2016), in which the structural changes in ENSO-related circulation can also be modified by the spatial pattern of the tropical Pacific SST increase via the atmospheric convection process (Cai et al. 2014b; Huang and Xie 2015). This result suggests that the oceanic mechanism proposed in Cai et al. (2014a) to explain the increased extreme pIOD events could form the structural changes in IOD SST and circulation. The pIOD-like mean-state SST changes (Fig. 1) associated with shoaling thermocline and weakening of equatorial eastward oceanic currents and westerly winds benefit the westward extension of the SSTAs in EEIO to form the structural changes in IOD SST and circulation relative to the historical patterns of IOD SST and circulation (Cai et al. 2014a). Because of the different change rates of $\Delta \omega_{a}^{\prime}, \Delta \omega_{s}^{\prime}, \Delta T_{a}^{\prime}$, and $\Delta T_{s}^{\prime}$, the pattern of $\Delta T^{\prime}=\Delta T_{a}^{\prime}+\Delta T_{s}^{\prime}$ is mismatched with that of $\Delta \omega^{\prime}=\Delta \omega_{a}^{\prime}+\Delta \omega_{s}^{\prime}$ shown in Fig. 4, although their subcomponents correspond well with each other (Fig. 5). This result disentangles the puzzle of the mismatch between $\Delta T^{\prime}$ and $\Delta \omega^{\prime}$ shown in Fig. 4 , which is crucial to understand the mismatch between $\Delta T^{\prime}$ and $\Delta P^{\prime}$ shown in Figs. 2c and 2d.

\section{Intermodel uncertainty and the effect of model bias}

Although CMIP5 models project a robust change in the structure of IOD SST and circulation associated with the pIOD-like mean-state SST changes (Fig. 1), Li et al. (2016) reported that the robust pIOD-like pattern of mean-state SST changes could be an artificial projection induced by the commonly overestimated IOD amplitude in the CMIP5 models, implying the projected increases in the extreme pIOD events would also be artificial. We defined a DMI-like SST index to represent the zonal pattern of mean-state SST changes in the models following Li et al. (2016), and used the standard deviation of DMI to represent the simulated historical IOD amplitude. Indeed, there are significant correlation between the zonal pattern of mean-state SST changes and the historical IOD amplitude among the models

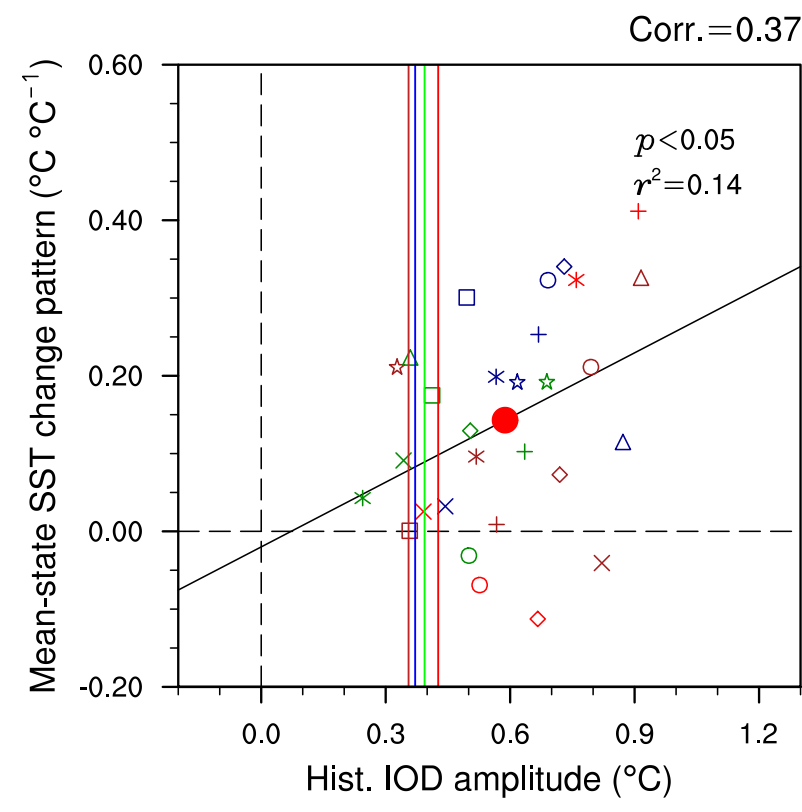

FIG. 9. Intermodel relationship of the zonal pattern of meanstate SST changes under global warming, scaled by the regionalmean SST increase, with the simulated historical IOD SST amplitude. The dark solid line denotes the linear regression; the blue, red, brown, and green solid lines denote the observed historical IOD SST amplitude in ERSST version 4, ERSST version 5, HadISST, and COBE SST2, respectively; and the correlation coefficient is shown in the top-right corner.

(Fig. 9), and the IOD amplitude is commonly overestimated in the models compared with the observation in four SST datasets ERSST version 4, ERSST version5, HadISST, and COBE SST2 (blue, red, brown, and green lines in Fig. 9, respectively) although the IOD amplitude in the four datasets shows some discrepancies varying from $0.37^{\circ}$ to $0.42^{\circ} \mathrm{C}$ (Cai and Cowan 2013; Liu et al. 2014; Li et al. 2015). Under a spatial observational constraint strategy (Boé et al. 2009; Bracegirdle and Stephenson 2012; Collins et al. 2012; Bracegirdle and Stephenson 2013; Cox et al. 2013; Huang and Ying 2015), we can see that the robust pIOD-like pattern of mean-state SST could be overestimated, being twice constrained by the IOD amplitude.

We further investigated the relationship between the zonal pattern of mean-state SST changes with the amplitude and structural changes of IOD circulation and SST. The mean-state SST change pattern is not significantly correlated with the change percentages of $\Delta \omega_{a}^{\prime}$ and $\Delta T_{a}^{\prime}$ (Fig. 10), further verifying that $\Delta \omega_{a}^{\prime}$ and $\Delta T_{a}^{\prime}$ are dominated by the increase in atmospheric stability increase (Fig. 7) and the spatial pattern of mean-state SST changes does not play a remarkable role. For the structural changes, the mean-state SST change pattern and the historical IOD amplitude both significantly 
(a)

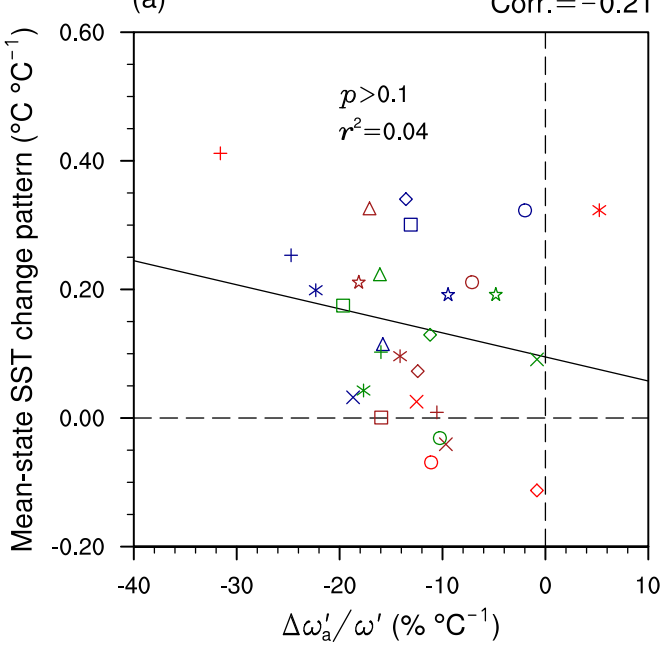

(b)

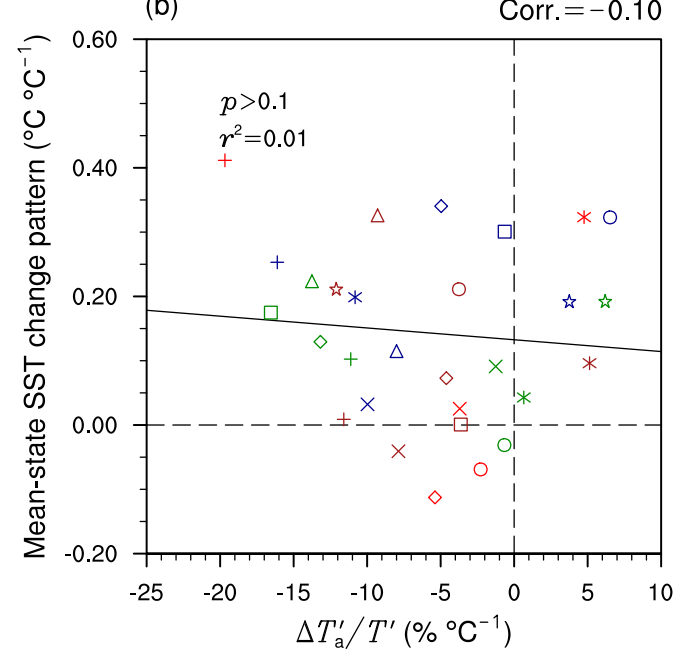

FIG. 10. Intermodel relationship of the zonal pattern of mean-state SST changes under global warming with the amplitude change percentage of (a) the IOD circulation and (b) IOD SST per $1^{\circ} \mathrm{C}$ global warming. The solid line denotes the linear regression, and the correlation coefficient is shown in the top-right corner of each panel.

correlate with $\Delta \omega_{s}^{\prime}$ and $\Delta T^{\prime}{ }_{s}$ (Figs. 11 and 12), no matter whether the intermodel spread of historical IOD amplitude associated with the sensitivity of air-sea coupling is removed from $\Delta \omega_{s}^{\prime}$ and $\Delta T_{s}^{\prime}$ in respective models (Figs. 11c,d and 12c,d) or not (Figs. 11a,b and 12a,b). While the historical IOD amplitude in the models is commonly overestimated with respect to the observations (Fig. 12), the robust structural changes in IOD circulation and IOD SST, associated with the increase in extreme pIOD events, could be overestimated. Even though there is a significant correlation of the historical IOD amplitude with the mean-state SST change pattern (Fig. 9), $\Delta \omega_{s}^{\prime}$ and $\Delta T^{\prime}{ }_{s}$ (Fig. 12), we must notice that the intermodel spread of historical IOD amplitude only can explain about $14 \%$ ( $r^{2}$ in Fig. 9) of the intermodel variance of the mean-state SST change pattern, and around $40 \%-50 \%\left(r^{2}\right.$ in Figs. 12a,b) of the intermodel variance of $\Delta \omega_{s}^{\prime}$ and $\Delta T^{\prime}{ }_{s}$. Therefore, the projected robust changes in $\Delta \omega^{\prime}$ and $\Delta T^{\prime}{ }_{s}$ with increased extreme pIOD events cannot be totally erased by the emergent constraint considering the overestimated historical IOD bias. Some other processes suggested in Wang et al. (2017) could also contribute to the mean-state SST change pattern and the structural changes in IOD circulation and SST.

\section{Conclusions and discussion}

The present study investigated the changes in IODrelated SST and rainfall variability under global warming through a moisture budget decomposition for IOD-related rainfall variability and an amplitude and structural decomposition for IOD-related SST and circulation variability, based on 29 CMIP5 models in RCP8.5 simulations. The results show that the moisture budget decomposition proposed for the changes in ENSO-related rainfall variability (Huang and Xie 2015) is also practicable to disentangle the changes in IOD rainfall. The changes in IOD-related circulation are closely related to the changes in IOD-related SST through the amplitude and structural decomposition.

The total IOD rainfall changes can be decomposed into a thermodynamic component due to the increase in mean-state moisture and a dynamic component induced by the changes in IOD circulation. The sum of the thermodynamic and dynamic components can accurately describe the pattern of IOD rainfall changes. The thermodynamic component enhances the amplitude of IOD rainfall with an identical pattern to the historical IOD rainfall, whereas the pattern of the dynamic component dominated by the pattern of IOD circulation changes features an increase from the EEIO to the western coast of the equatorial IO.

The moisture budget decomposition converts the question of IOD rainfall changes to that of IOD circulation changes. We further decomposed the changes in IOD SST and circulation into the amplitude and structural components, inspired by the success of a similar decomposition in Huang and Xie (2015) to reveal the close relationship between the changes in ENSO-related circulation and SST variability. The amplitude changes in IOD circulation $\Delta \omega^{\prime}{ }_{a}$ are significantly correlated with that of IOD SST among the models $\Delta T^{\prime}{ }_{a}$, both of which show a robust decrease. Moreover, the decrease rate of 
(a)

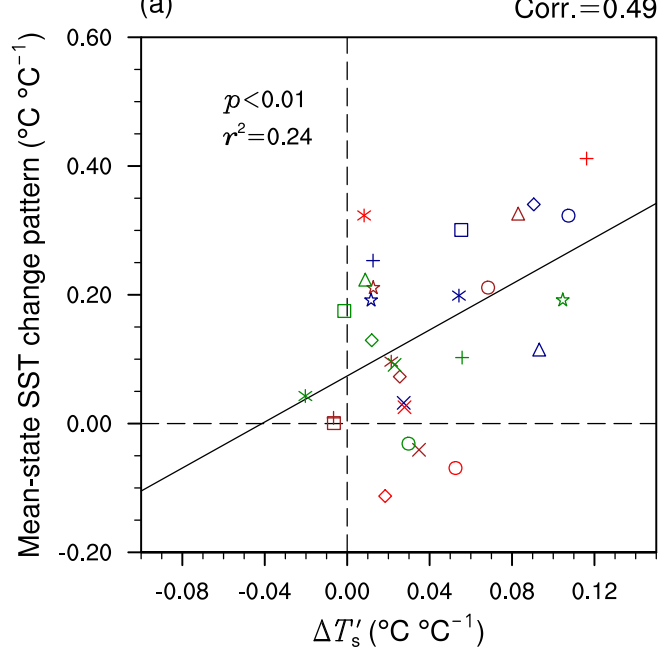

(c)

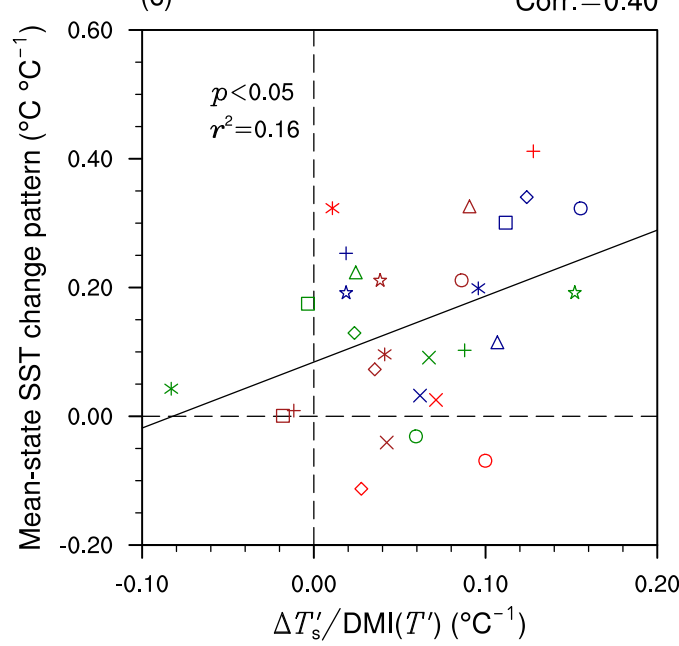

(b)

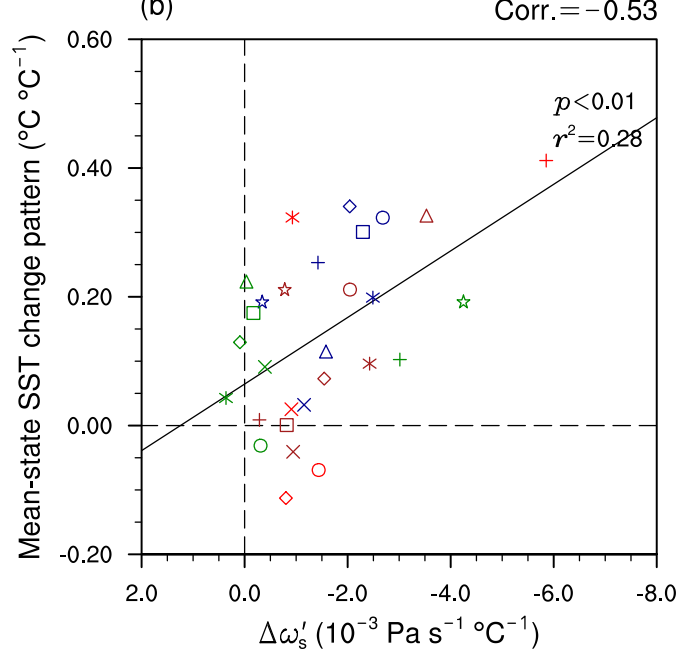

(d)

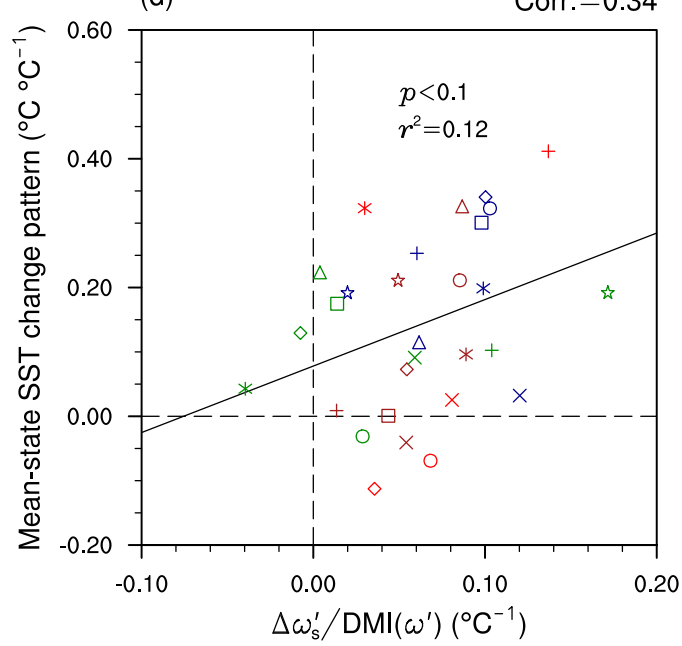

FIG. 11. Intermodel relationship of the zonal pattern of mean-state SST changes with the structural changes in (a) IOD SST and (b) IOD circulation per $1^{\circ} \mathrm{C}$ global warming. (c),(d) The amplitudes of historical IOD SST and circulation are removed from the structural changes in IOD SST and circulation, respectively. The solid line denotes the linear regression, and the correlation coefficient is shown in the top-right corner of each panel.

$\Delta \omega^{\prime}{ }_{a}$, around $13.7 \%{ }^{\circ} \mathrm{C}^{-1}$, is about twice of the decrease rate of $\Delta T^{\prime}{ }_{a}$ because of the decrease in the response of atmospheric circulation to local SST anomalies under global warming (P. Huang et al. 2017). In turn, the decreased atmospheric response to local SST anomalies suppresses the variability of IOD SST. The pattern of the structural changes in IOD circulation is similar to that of the structural changes in IOD SST, similar to the pattern of the extreme IOD rainfall defined in Cai et al. (2014a).

The present study can more clearly explain two conflicting processes resulting in an uncertain IOD change suggested in Zheng et al. (2013). The suppression of increased atmospheric stability is basically uniform
(P. Huang et al. 2017) and mainly results in the amplitude changes of IOD, whereas the pIOD-like mean-state SST changes associated with the shoaling thermocline mainly modify the structure of IOD as suggested in Cai et al. (2014a). Both of them are robust in the CMIP5 projections, but because of the distinct patterns between them the predefined DMI changes would project an uncertain IOD change. Another noteworthy result is that the time scale of the response of IOD SST with circulation to global warming could be different between their amplitude and structural changes: the amplitude changes could be more exactly linear along with the tropical-mean temperature increase, whereas the structural change shows pronounced 

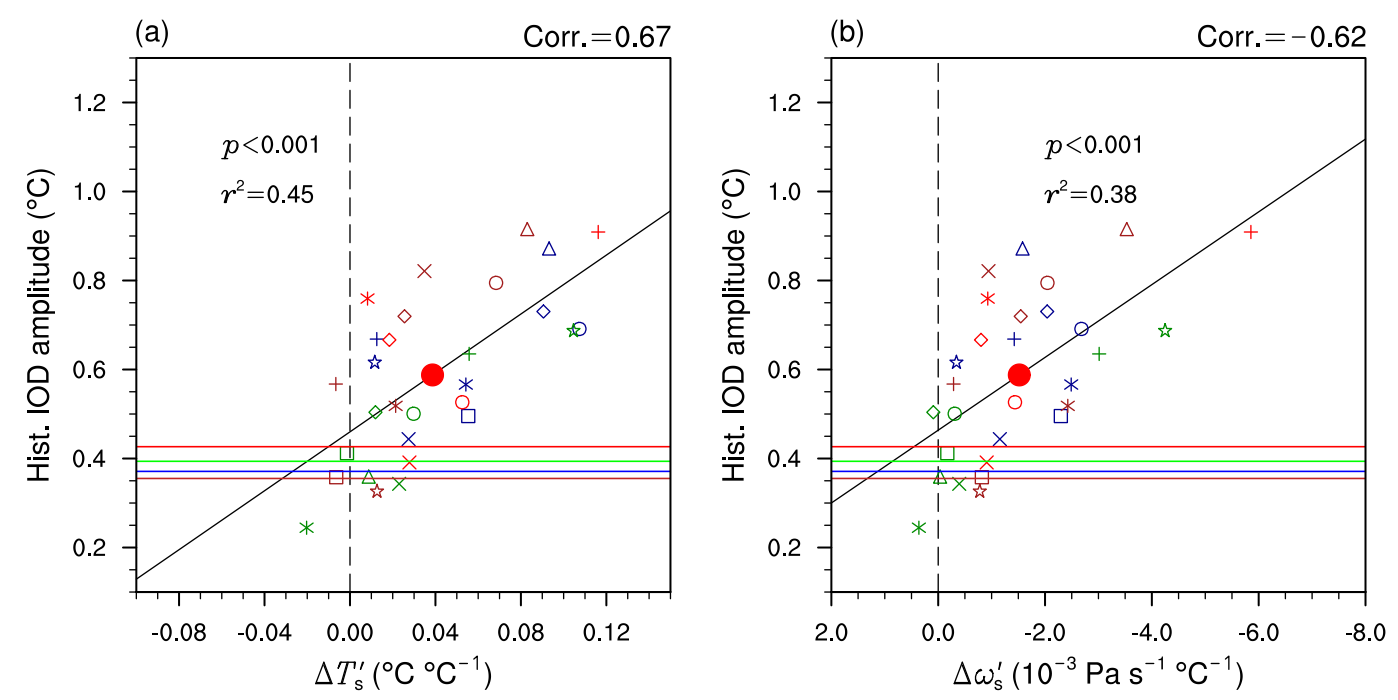

(c) Corr. $=0.50$
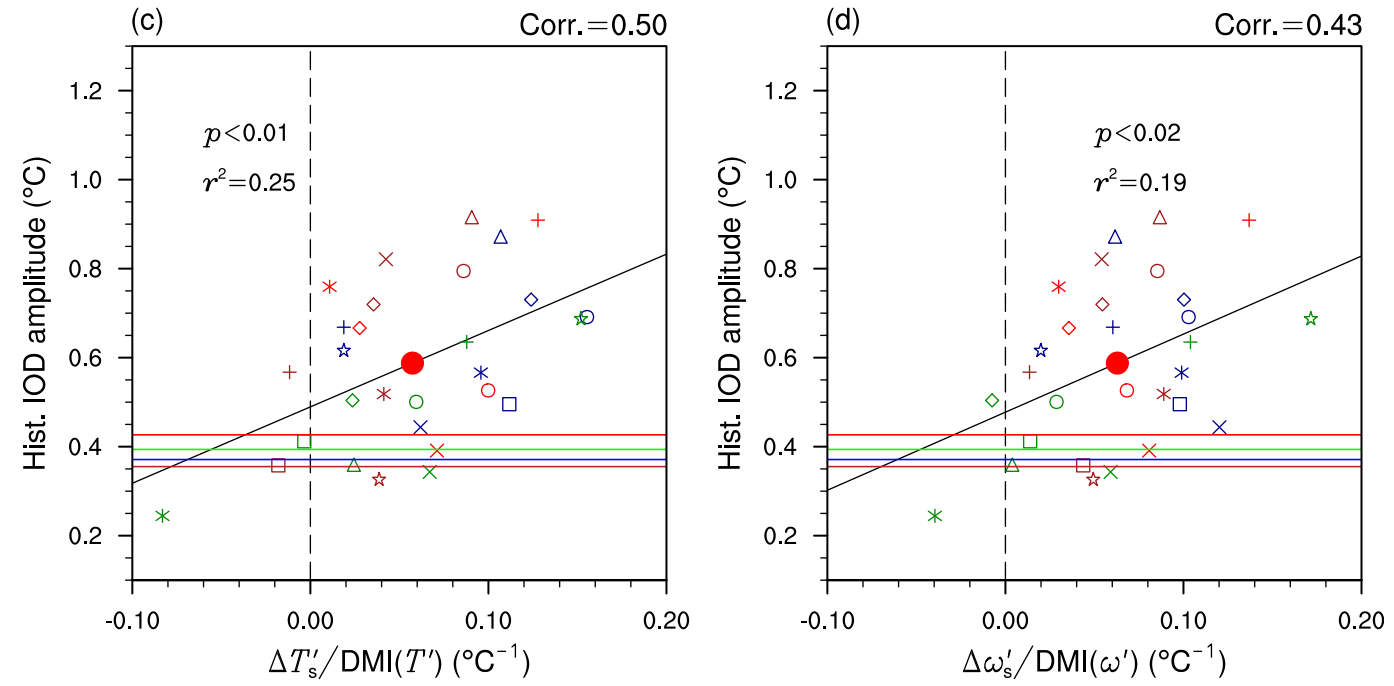

FIG. 12. As in Fig. 11, but the vertical coordinates represent the historical IOD SST amplitude. The blue, red, brown, and green solid lines denote the observed historical IOD SST amplitude in ERSST version 4, ERSST version 5, HadISST, and COBE SST2, respectively. The red point denotes the MME of the simulated historical IOD SST amplitude and the structural changes in IOD SST and circulation.

differences between the early and late twenty-first century.

The intermodel spread analysis for the structural changes in IOD SST and circulation indicates that the robust structural changes in IOD SST and circulation are significantly associated with the pIOD-like pattern of mean-state SST changes, which could be overestimated by the common overly IOD amplitude in the models ( $\mathrm{Li}$ et al. 2016). When this bias is considered in the emergent constraint, the robust structural changes in IOD SST and circulation associated with the extreme pIOD evernts projected in the CMIP5 models should be weakened. However, only a part of intermodel variance of the mean-state SST change pattern (around 14\%) and $\Delta T^{\prime}{ }_{s}$ (around $40 \%-50 \%$ ) can be explained by the historical IOD amplitude. This agrees with the suggestions in Wang et al. (2017) that there could be other mechanisms also contribute to the robust structural changes in IOD circulation and SST, which cannot be erased by the emergent constraint with the IOD amplitude bias.

The present study only analyzed the changes under the RCP8.5 scenario, which could be different from the changes in other pathway scenarios. However, this issue could not influence the main conclusions drawn in the present study. First, the moisture budget 
decomposition for IOD rainfall change was checked for the other 17 periods with lower warming except for the period 2066-95. The moisture budget decomposition can also accurately describe the IOD rainfall changes in the lower warming scenarios as in 2066-95 (not shown). Second, the amplitude and structural decompositions for IOD SST and circulation changes in lower warming scenarios have been shown in Figs. 7 and 8. The relationships of the amplitude and structural changes in IOD SST and circulation with tropical-mean warming are mainly linear, and the main conclusions drawn here were also based on these linear relationships. Indeed, there are some obvious nonlinear evolutions in the structural changes of IOD SST and circulation (Figs. 8b,c). It could reflect the nonunidirectional response of mean SST to global warming over the Indo-Pacific basin (Kim et al. 2014) and be associated with the scenarios, which would be an interesting issue in the future.

All of the present conclusions are based on the initial definition of IOD, the regression onto the DMI. This method greatly locks the related patterns to correlate with the dipole pattern of the two regions to calculate DMI both in the present-day and future climate. As a result, the possible changes independent of the DMI, such as the so-called extreme IOD events based on the second EOF mode of IO SST anomalies, are greatly removed relative to the results based on EOF analysis (Cai et al. 2013; Zheng et al. 2013). Even so, there are remarkable structural changes found in the DMIregressed IOD SST and circulation patterns. This result implies that the structural changes in the IOD pattern could be underestimated in this study. The distinct method could also contribute to the more robust projections in the amplitude and structural changes of the IOD SST and circulation (Figs. 5 and 6). The method removed some structural changes and simplified the question to obtain a clearer conclusion, which would be a solid foundation to further study other aspects of IOD changes in future.

Acknowledgments. The work was supported by the National Natural Science Foundation of China (Grants 41722504, 41476003, 41575088, 41706024, 41690121, and 41690120), the Youth Innovation Promotion Association CAS, and the Fundamental Research Funds for the Central Universities. I acknowledge the World Climate Research Programme's Working Group on Coupled Modeling, which is responsible for CMIP5, and the climate modeling groups (listed in section 2a) for producing and making available their model output. We also thank two anonymous reviewers for their constructive suggestions.

\section{REFERENCES}

Abram, N. J., M. K. Gagan, J. E. Cole, W. S. Hantoro, and M. Mudelsee, 2008: Recent intensification of tropical climate variability in the Indian Ocean. Nat. Geosci., 1, 849-853, https://doi.org/10.1038/ngeo357.

Ashok, K., Z. Guan, and T. Yamagata, 2003: Influence of the Indian Ocean dipole on the Australian winter rainfall. Geophys. Res. Lett., 30, 1821, https://doi.org/10.1029/2003GL017926.

Behera, S. K., J. J. Luo, S. Masson, P. Delecluse, S. Gualdi, A. Navarra, and T. Yamagata, 2005: Paramount impact of the Indian Ocean dipole on the East African short rains: A CGCM study. J. Climate, 18, 4514-4530, https://doi.org/10.1175/ JCLI3541.1.

Boé, J., A. Hall, and X. Qu, 2009: September sea-ice cover in the Arctic Ocean projected to vanish by 2100 . Nat. Geosci., 2, 341343, https://doi.org/10.1038/ngeo467.

Bracegirdle, T. J., and D. B. Stephenson, 2012: Higher precision estimates of regional polar warming by ensemble regression of climate model projections. Climate Dyn., 39, 2805-2821, https://doi.org/10.1007/s00382-012-1330-3.

— and - 2013: On the robustness of emergent constraints used in multimodel climate change projections of Arctic warming. J. Climate, 26, 669-678, https://doi.org/10.1175/ JCLI-D-12-00537.1.

Cai, W., and T. Cowan, 2013: Why is the amplitude of the Indian Ocean dipole overly large in CMIP3 and CMIP5 climate models? Geophys. Res. Lett., 40, 1200-1205, https://doi.org/ 10.1002/grl.50208.

_ , and Coauthors, 2013: Projected response of the Indian Ocean dipole to greenhouse warming. Nat. Geosci., 6, 999-1007, https://doi.org/10.1038/ngeo2009.

— dian Ocean dipole events due to greenhouse warming. Nature, 510, 254-258, https://doi.org/10.1038/nature13327.

- , and Coauthors, 2014b: Increasing frequency of extreme El Niño events due to greenhouse warming. Nat. Climate Change, 4, 111-116, https://doi.org/10.1038/nclimate2100.

Capotondi, A., M. A. Alexander, N. A. Bond, E. N. Curchitser, and J. D. Scott, 2012: Enhanced upper ocean stratification with climate change in the CMIP3 models. J. Geophys. Res. Oceans, 117, C04031, https://doi.org/10.1029/2011JC007409.

Chou, C., J. D. Neelin, C. Chen, and J. Tu, 2009: Evaluating the "rich-get-richer" mechanism in tropical precipitation change under global warming. J. Climate, 22, 1982-2005, https:// doi.org/10.1175/2008JCLI2471.1.

Chung, C. T. Y., S. B. Power, J. M. Arblaster, H. A. Rashid, and G. L. Roff, 2014: Nonlinear precipitation response to El Niño and global warming in the Indo-Pacific. Climate Dyn., $\mathbf{4 2}$, 1837-1856, https://doi.org/10.1007/s00382-013-1892-8.

Collins, M., and Coauthors, 2010: The impact of global warming on the tropical Pacific Ocean and El Niño. Nat. Geosci., 3, 391397, https://doi.org/10.1038/ngeo868.

- R. E. Chandler, P. M. Cox, J. M. Huthnance, J. Rougier, and D. B. Stephenson, 2012: Quantifying future climate change. Nat. Climate Change, 2, 403-409, https://doi.org/10.1038/ nclimate1414.

Cox, P. M., D. Pearson, B. B. Booth, P. Friedlingstein, C. Huntingford, C. D. Jones, and C. M. Luke, 2013: Sensitivity of tropical carbon to climate change constrained by carbon dioxide variability. Nature, 494, 341-344, https://doi.org/10.1038/nature11882.

Dong, L., L. R. Leung, and F. Song, 2018: Future changes of subseasonal precipitation variability in North America during 
winter under global warming. Geophys. Res. Lett., 45, $12467-$ 12 476, https://doi.org/10.1029/2018GL079900.

Du, Y., and S.-P. Xie, 2008: Role of atmospheric adjustments in the tropical Indian Ocean warming during the 20th century in climate models. Geophys. Res. Lett., 35, L08712, https:// doi.org/10.1029/2008GL033631.

Held, I. M., and B. J. Soden, 2006: Robust responses of the hydrological cycle to global warming. J. Climate, 19, 5686-5699, https://doi.org/10.1175/JCLI3990.1.

Hirahara, S., M. Ishii, and Y. Fukuda, 2014: Centennial-scale sea surface temperature analysis and its uncertainty. J. Climate, 27, 57-75, https://doi.org/10.1175/JCLI-D-12-00837.1.

Huang, B., and Coauthors, 2015: Extended reconstructed sea surface temperature version 4 (ERSST.V4). Part I: Upgrades and intercomparisons. J. Climate, 28, 911-930, https://doi.org/ 10.1175/JCLI-D-14-00006.1.

— , and Coauthors, 2017: Extended reconstructed sea surface temperature, version 5 (ERSSTv5): Upgrades, validations, and intercomparisons. J. Climate, 30, 8179-8205, https:// doi.org/10.1175/JCLI-D-16-0836.1.

Huang, P., 2014: Regional response of annual-mean tropical rainfall to global warming. Atmos. Sci. Lett., 15, 103-109, https:// doi.org/10.1002/asl2.475.

_ 2016: Time-varying response of ENSO-induced tropical Pacific rainfall to global warming in CMIP5 models. Part I: Multimodel ensemble results. J. Climate, 29, 5763-5778, https://doi.org/10.1175/JCLI-D-16-0058.1.

_ , and S.-P. Xie, 2015: Mechanisms of change in ENSO-induced tropical Pacific rainfall variability in a warming climate. Nat. Geosci., 8, 922-926, https://doi.org/10.1038/ngeo2571.

— , and J. Ying, 2015: A multimodel ensemble pattern regression method to correct the tropical Pacific SST change patterns under global warming. J. Climate, 28, 4706-4723, https:// doi.org/10.1175/JCLI-D-14-00833.1.

_ , S.-P. Xie, K. Hu, G. Huang, and R. Huang, 2013: Patterns of the seasonal response of tropical rainfall to global warming. Nat. Geosci., 6, 357-361, https://doi.org/10.1038/ngeo1792.

- I.-I. Lin, C. Chou, and R. Huang, 2015: Change in ocean subsurface environment to suppress tropical cyclone intensification under global warming. Nat. Commun., 6, 7188, https://doi.org/10.1038/ncomms8188.

- - D. Chen, and J. Ying, 2017: Weakening of the tropical atmospheric circulation response to local sea surface temperature anomalies under global warming. J. Climate, 30, 8149-8158, https://doi.org/10.1175/JCLI-D-17-0171.1.

Hui, C., and X.-T. Zheng, 2018: Uncertainty in Indian Ocean dipole response to global warming: The role of internal variability. Climate Dyn., 51, 3597-3611, https://doi.org/10.1007/s00382018-4098-2.

Ihara, C., Y. Kushnir, M. A. Cane, and V. H. de La Peña, 2009: Climate change over the equatorial Indo-Pacific in global warming. J. Climate, 22, 2678-2693, https://doi.org/10.1175/ 2008JCLI2581.1.

Kim, S. T., W. Cai, F.-F. Jin, A. Santoso, L. Wu, E. Guilyardi, and S.-I. An, 2014: Response of El Niño sea surface temperature variability to greenhouse warming. Nat. Climate Change, 4, 786-790, https://doi.org/10.1038/nclimate2326.

Knutson, T. R., and S. Manabe, 1995: Time-mean response over the tropical Pacific to increased $\mathrm{CO}_{2}$ in a coupled oceanatmosphere model. J. Climate, 8, 2181-2199, https://doi.org/ 10.1175/1520-0442(1995)008<2181:TMROTT>2.0.CO;2.

Kripalani, R. H., J. H. Oh, and H. S. Chaudhari, 2010: Delayed influence of the Indian Ocean dipole mode on the East
Asia-west Pacific monsoon: Possible mechanism. Int. J. Climatol., 30, 197-209, https://doi.org/10.1002/joc.1890.

Li, G., S.-P. Xie, and Y. Du, 2015: Monsoon-induced biases of climate models over the tropical Indian Ocean. J. Climate, 28, 3058-3072, https://doi.org/10.1175/JCLI-D-14-00740.1.

,-- , and -2016 : A robust but spurious pattern of climate change in model projections over the tropical Indian Ocean. J. Climate, 29, 5589-5608, https://doi.org/10.1175/ JCLI-D-15-0565.1.

Liu, L., S.-P. Xie, X.-T. Zheng, T. Li, Y. Du, G. Huang, and W.-D. $\mathrm{Yu}, 2014$ : Indian Ocean variability in the CMIP5 multi-model ensemble: The zonal dipole mode. Climate Dyn., 43, 17151730, https://doi.org/10.1007/s00382-013-2000-9.

Liu, W., J. Lu, and S. Xie, 2015: Understanding the Indian Ocean response to double $\mathrm{CO}_{2}$ forcing in a coupled model. Ocean Dyn., 65, 1037-1046, https://doi.org/10.1007/s10236015-0854-6.

Lu, J., G. Chen, and D. M. W. Frierson, 2008: Response of the zonal mean atmospheric circulation to $\mathrm{El}$ Niño versus global warming. J. Climate, 21, 5835-5851, https://doi.org/10.1175/ 2008JCLI2200.1.

Luo, Y., J. Lu, F. Liu, and X. Wan, 2016: The positive Indian Ocean dipole-like response in the tropical Indian Ocean to global warming. Adv. Atmos. Sci., 33, 476-488, https://doi.org/ 10.1007/s00376-015-5027-5.

Murtugudde, R., J. P. McCreary, and A. J. Busalacchi, 2000: Oceanic processes associated with anomalous events in the Indian Ocean with relevance to 1997-1998. J. Geophys. Res. Oceans, 105, 3295-3306, https://doi.org/10.1029/1999JC900294.

Pierce, D. W., T. P. Barnett, K. M. AchutaRao, P. J. Gleckler, J. M. Gregory, and W. M. Washington, 2006: Anthropogenic warming of the oceans: Observations and model results. J. Climate, 19, 1873-1900, https://doi.org/10.1175/JCLI3723.1.

Power, S., F. Delage, C. Chung, G. Kociuba, and K. Keay, 2013: Robust twenty-first-century projections of El Niño and related precipitation variability. Nature, 502, 541-545, https://doi.org/ 10.1038/nature12580.

Rayner, N. A., and Coauthors, 2003: Global analyses of sea surface temperature, sea ice, and night marine air temperature since the late nineteenth century. J. Geophys. Res., 108, 4407, https://doi.org/10.1029/2002JD002670.

Saji, N., B. Goswami, P. Vinayachandran, and T. Yamagata, 1999: A dipole mode in the tropical Indian Ocean. Nature, 401, 360 363, https://doi.org/10.1038/43854.

Schott, F. A., S. P. Xie, and J. P. McCreary, 2009: Indian Ocean circulation and climate variability. Rev. Geophys., 47, RG1002, https://doi.org/10.1029/2007RG000245.

Seager, R., N. Naik, and G. A. Vecchi, 2010: Thermodynamic and dynamic mechanisms for large-scale changes in the hydrological cycle in response to global warming. J. Climate, 23, 4651-4668, https://doi.org/10.1175/2010JCLI3655.1.

,-- , and L. Vogel, 2012: Does global warming cause intensified interannual hydroclimate variability? J. Climate, 25, 3355-3372, https://doi.org/10.1175/JCLI-D-11-00363.1.

Taylor, K. E., R. J. Stouffer, and G. A. Meehl, 2012: An overview of CMIP5 and the experiment design. Bull. Amer. Meteor. Soc., 93, 485-498, https://doi.org/10.1175/BAMS-D-11-00094.1.

Tedeschi, R. G., and M. Collins, 2017: The influence of ENSO on South American precipitation: Simulation and projection in CMIP5 models. Int. J. Climatol., 37, 3319-3339, https://doi.org/ 10.1002/joc.4919.

Wang, G., W. Cai, and A. Santoso, 2017: Assessing the impact of model biases on projected increase in frequency of extreme 
positive Indian Ocean dipole events. J. Climate, 30, 2757-2767, https://doi.org/10.1175/JCLI-D-16-0509.1.

Webster, P. J., A. M. Moore, J. P. Loschnigg, and R. R. Leben, 1999: Coupled ocean-atmosphere dynamics in the Indian Ocean during 1997-98. Nature, 401, 356-360, https://doi.org/ $10.1038 / 43848$

Yamagata, T., S. K. Behera, J.-J. Luo, S. Masson, M. R. Jury, and S. A. Rao, 2004: Coupled ocean-atmosphere variability in the tropical Indian Ocean. Earth's Climate: The OceanAtmosphere Interaction, Geophys. Monogr., No. 147, Amer. Geophys. Union, 189-212.

Yu, L. S., and M. M. Rienecker, 1999: Mechanisms for the Indian Ocean warming during the 1997-98 El Niño.
Geophys. Res. Lett., 26, 735-738, https://doi.org/10.1029/ 1999GL900072.

Zheng, X.-T., S.-P. Xie, G. A. Vecchi, Q. Liu, and J. Hafner, 2010: Indian Ocean dipole response to global warming: Analysis of ocean-atmospheric feedbacks in a coupled model. J. Climate, 23, 1240-1253, https://doi.org/10.1175/2009JCLI3326.1.

_ - Y. Du, L. Liu, G. Huang, and Q. Liu, 2013: Indian Ocean dipole response to global warming in the CMIP5 multimodel ensemble. J. Climate, 26, 6067-6080, https:// doi.org/10.1175/JCLI-D-12-00638.1.

Zubair, L., S. A. Rao, and T. Yamagata, 2003: Modulation of Sri Lankan Maha rainfall by the Indian Ocean dipole. Geophys. Res. Lett., 30, 1063, https://doi.org/10.1029/2002GL015639. 